seems to be little doubt, surely such a recommendation must be not obly unscientific but worse than useless. Such advice $I$ am inclined to think it is, that has so generally driven the treatment of such cases into the hands of empirics.

Mr. Dudgeon, however, approaches my views much more nearly than Mr. Chatto. He admits that "many can abstain from breaking this law of morality without having their health injured," and for this great concession I am, also, most willing to admit with him that some constitutions are naturally predisposed to this disease. The rock upon which he seems to me to have foundered is the extent of his credulity. But for this, we should hold the same opinions. Let me remind him that, in arriving at any conclusion as to the real cause of spermatorrhoea, it must never be overlooked that it is a disease of a class which, more than any other, renders the patient indisposed to assign the true one. If continence is allowed as a plea (which, I contend, it never can be, except with some great and evident constitutional peculiarity) it is not likely that the patient should refer it to incontinence. A person will rarely throw so great a reflection, even in confidence, on his moral character, if there be any loophole of escape, any way by which he may avoid it. No; I repeat, continence cannot cause it, and if Mr. Dudgeon reflects upon it I think he will soon admit this, and enter the ranks on the side of morality, for, if I am not mistaken, he has both candour and liberality enough to do so, as soon as he shall become convinced that it is the true one.

I have now, I trust, Mr. Editor, sulficiently aroused the attention of the profes. sion to this subject, and having, I believe, answered all the arguments adduced by the gentlemen who honoured me by replying to my first letter ; having endeavoured, to the best of my ability, to uphold physiology, and prevent the perversion of her admirable laws to the sanction of immorality and the encouragement of vice, I take leave of the subject, with the hope, however, that it may not lest here. May other and more able pens, whose directors have a greater inclination than I have for a public controversy, be exercised on this subject. They cannot be occupied more nobly, and I venture to assert that they cannot take firmer ground than when they shall attempt to maintain that THE LAWS OF PHYSIOLOGY ARE NEVER OPPOSED TO THOSE OF MORALITY; and, with reference to the present subject, that CONTINENCE CAN NEVER CAUSE SPERMATORRHEA, OR BE PRODUCTIVE OF ANY OTHER EVIL CONSEQUENCES TO THE SYSTEM, I am, Sir, your most abedient servant,

Henry Bull, M.D., Edin., M.R.C.S.L. \& E., \&c.

Hereford, Dec. 30, 1813.

P.S.-I do not see The Lancet until a No, 1062 . week after publication, therefore, on the present occasion, I have lost no time in writing the above letter, with the hope that you will be able to find room for it in your next NUMBER.

*** Our correspondent will, ere long, be enabled to see THE LanceT on his table at Hereford on the day that it is published in London.-ED. $\mathbf{L}$.

\section{RELIEF IN CASES OF LYSSA.}

To the Editor.-Sir: Attracted by your editorial remarks at page 337 , of THE LA NCET, in connection with an interesting letter of $\mathrm{Mr}_{\mathrm{r}}$. Turner, in which be recom. mends a trial of tracheotomy in the early stage of hydrophobia, I beg to forward a communication I had written, and intended to send to one of the medical journals many months ago. It was withheld only from a friend jocosely remarking that I should certainly be elected to the council of the besieged town. More than ever satisfied that the suggestion is not unworthy of consideration, I now beg the favour of its insertion in your columns. Our scientific friends, the veteriuarians, unfortunately cannot put it in practice, for their patients have no uvula. In consequence of the remarks of Mr. Youatt I am inclined to ask, $I_{s}$ it the presence of the uvula which makes the spasm of the glottis so much more marked in man than in the lower animals? I am, Sir, your obedient servant,

Saville-row, Dec. 23, 1843 .

"I am induced, by the recent prevalence of hydrophobia, to throw out a suggestion relative to the treatment of that terrible and fatal disease. The most efficacious remedial means in spasmodic disorders allied to hydrophobia are, undoubtedly, those which in . flict a sudden shock upon the nervous sys. tem. Excessive spasmodic action about the throat is well known to be a most prominent, and, probably, fatal symptom of the disease. It is this which occasions the difficulty of swallowing, and the extreme agony at the sight of liquids, or the bare idea of drinking or deglutition. Now, as excision of the uvula possesses in some cases a remarkable influence in controlling spasmodic action of the vocal and respiratory organs, it has occurred to me that it would be useful to perform this simple operation, as a slight shock to the nervous system, in the early or formative stage of hydrophobic disease. I have long intended to put this proposal to the test, should a case pass under my notice ; may I hope the publication of the present letter will lead to a trial of its efficacy earlier than might otherwise occur. With the exception of the unsuccessful experiment of Magendie, of producing in an hydrophobio $2 \mathrm{~K}$ 
patient an artificial repletion by the injection of large quantities of water into the veins, I do not know of any surgical plan that has been tried since the proposal of Marochetti to puncture the cluster of small pustules said to be found under the tongue. Of late years there have been very few novel propositions for the relief of rabies, and as the most powerful medicines prove utterly inefficacious, it seems to me that a surgical operation, such as that $I$ have mentioned, is deserving of performance. It certainly would entail no risk, and would have a local action upon the parts most implicated in this frightful malady. In favour of local remedies, I may instance a recent case at King's College Hospital, under Dr. Guy, on the whole one of the most successful ever published; where ice was applied unremittingly to the throat, with the effect of greatly moderating the convulsive struggles of the unfortunate patient.

"I do not wish this to be considered as more than a mere suggestion, resting entirely on my own responsibility, which I make with a hope that it may prove useful, but without any established data on which to rest an expectation of its success."

\section{KING'S COLLEGE HOSPITAL.}

\section{A S E S, \\ WITI CLINICAL OBSERVATIONS, BY MR. FERGUSSON.}

\section{HARE-LIP.-OPERATIONS ON INPANTS.}

Rebecca WATts, etat. three weeks, has a hare-lip fissure on the left side of the mesial line, for which the parents (both free from such malformation) are anxious an operation should be performed.

Oct. 7, 1843. To-day the margins of the fissure were pared with a narrow sharppointed bistoury, and the surfaces were retained in apposition by means of two twisted sutures. The proceedings occupied a very brief space of time, there was little loss of blood, and the child seemed to experience no great annoyance or suffering. Soon after its removal from the theatre it fell asleep.

9. Needles removed this morning; union apparently complete.

21. Has been brought several times to the hospital since last report. For the first week the upper lip was considerably swollen, but the tumefaction has now gone, and the part appear's in a most satisfactory condition. The cicatrix is scarcely observable, unless on a close inspection. The child appears in excellent health, and has taken the breast regularly since the operation was performed.

In some observations afterwards delivered on this case, it was stated by Mr. Fergusson that there were various interesting points connected with it worthy of the attention of the pupils; and he should advert to some of them, chiefly on the ground that the operation itself, being one of little magnitude, was apt to receive less of their consideration than others of a more imposing character, but which were, nevertheless, of rarer occurrence in ordinary practice, and possibly, too, occasionally of more questionable utility!

After describing the nature of the malformation, Mr. Fergusson referred to the advantages of an operation. Some infants, he said, were observed to suck with diffculty when the lip was thus split; but the propriety of performing an operation to remedy this defect was doubtful; for, pos. sibly, the child thus treated might immediately after refuse the breast altogether. As regarded speech, such a question was of little consequence during the infancy of a patient ; and, perhaps, at this period of life, and, indeed, in all after years, the chief in. ducement towards an operation had refer. ence to personal appearance. On this score there was good reason for interference, as neither parents nor friends could have much gratification in looking upon a child thus conspicuously marked; and, therefore, it only remained a question as to the best period for the performance of an operation. His own opinion was that, under all circumstances, the best period was immediately after suckling, provided the patient appeared in good health, and did not seem to suffer from teething. Here, as in all other cases about to be subjected to operation, it was the duty of the surgeon to examine as to the state of the system generally, and such being satisfactory, be imagined that there was no safer opportunity than that referred to. Some, however, had urged that a later age should be selected, while others had chosen an earlier; of the two, he should prefer the latter, although, indeed, it seemed to him to be, in the generality of cases, more a matter of choice as to will or convenience, when the proceeding should be done; for, usually, it was a very safe operation at all periods of life. He gave preference to the early age, as the patient was then more manageable, and he stated that he had experienced most trouble with those about eight years old, as the struggles of the sufferers were then more difficult of control. At a later age, again, the parties were usually very desirous to submit to the surgeon, and had sufficient command over themselves to keep perfectly steady. In the case under notice he had recommended delay for a 